Marshall, C. R. \& Walkley, V. T. (1952). J. gen. Microbiol. 6, 377-381.

\title{
On the Presence of Acetobacter oxydans in Apple Juice
}

\author{
By C. R. MARSHALL AND V. T. WALKLEY \\ Seager, Evans and Co. Ltd., 14 Deptford Bridge, London, S.E. 8
}

SUMMARY: Acetobacter oxydans has been identified in pure natural apple juice. A new technique which possesses some advantages over existing methods has been developed for demonstrating capsule formation by this organism and by other species of Acetobacter.

Grove (1915) isolated five different types of acetic acid bacteria from thirty to forty ciders and described their cultural characters when grown in malt extract solution containing $2 \%$ ethanol; the most commonly occurring was Bacterium xylinum but the others were not identified. Vandecaveye (1927) reported two strains of vinegar bacteria which did not form a pellicle, observed during an examination of cider vinegar. These organisms produced large quantities of acetic acid in fermented ciders and were catalase positive. Using their oxidative powers as a basis of differentiation between the species, he identified his strains as Acetobacter aceticum and $A$. rancens.

During the course of a microbiological investigation carried out at a commercial apple juice factory in Gloucestershire, we isolated and identified a large number of yeasts, moulds, and bacteria present on the fruit that were capable of inducing spoilage in apple juice. Their ability to develop in apple juice and their resistance to pasteurization were observed and will be reported elsewhere. Among the bacteria encountered were two species of Acetobacter, of which one was identified as $A$. xylinum Brown, similar to Bact. xylinum found in cider by Grove. The other species appeared to be a variety of $A$. oxydans (Henneberg) Bergey et al. Since the presence of this latter organism in apple juice has not hitherto been recorded we describe its characters in the present paper.

It was first isolated from a mixed plate culture which had been seeded with a sample of apple juice taken after several months' bulk storage at $37^{\circ}$ of a heavily carbonated juice. The incidence of the organism increased from the third to the tenth month of storage to a maximum of 900 organisms $/ \mathrm{ml}$. juice. Thereafter, a decrease was observed, and 6 months later the organism was detected with difficulty. High carbonation and low temperature sufficiently arrested its development and prevented any impairment of the organoleptic properties of the juice. Subsequent investigations showed that it was frequently present on the apples used for processing and its presence in the juice was ascribed to this source.

\section{METHODS}

Bergey's Manual (1948) has reclassified the entire group of vinegar bacteria under the genus Acetobacter, all species possessing the common characteristic of forming at some period of their development either a pellicle or a surface film on the surface of suitable liquid media. It describes seven principal 
species, together with two species considered by Beijerinck to be varieties of $A$. rancens, and also seventeen ancillary species which it is declared require further study before any change in nomenclature is advisable.

As a group the acetic acid bacteria are all Gram-negative, non-spore forming, and give a negative response to the Voges-Proskauer reaction. They oxidize ethanol to acetic acid, and various organic compounds to organic acids. Walker \& Tošic (1943) have stated that, with the exception of $A$. peroxydans, all known Acetobacter species are catalase positive. Kulka \& Walker (1946) established that capsule formation also is probably a characteristic feature of the genus. The keys to the identification of certain species given by Bergey's Manual (1948), Shimwell (1948), and Walker \& Tošić (1946a,b), were found helpful for identifying our isolates.

Media. Apple juice and Blickfeldt's solution were used as liquid media. These solutions were used for preparation of solid media with $2 \%$ agar, but for this purpose apple juice was usually diluted to decrease the sugar content to $1-2 \%$ and $0.2 \% \mathrm{w} / \mathrm{v}\left(\mathrm{NH}_{4}\right)_{2} \mathrm{HPO} 4$ added.

Gram reaction. The reliability of the staining technique was checked by mixing together on the slide containing the unknown organism a Gram-positive organism (Micrococcus candidus) and a Gram-negative organism (Bacterium coli).

Catalase test, was carried out according to the method used by Walker \& Tošić (1943) using sterile malt extract (sp.gr. 1036) buffered with $\mathrm{CaCO}_{3}$ and solidified with $1.5 \%$ agar.

Biochemical reactions were conducted in yeast water with addition of $1 \%(\mathrm{w} / \mathrm{v})$ of the appropriate sugar or organic substrate. The tests were incubated at $25^{\circ}$ and the tubes examined at intervals up to 2 weeks.

Capsule staining. To a $5 \%(\mathrm{w} / \mathrm{v})$ solution of gelatin in water at $60^{\circ}$ sufficient Cotton Blue powder is added to give an intense dark blue colour forming the contrast medium, powdered eosin $(1-2 \%)$ is then added, and the whole thoroughly mixed. Films are prepared on a warm stage at $30-37^{\circ}$. A little of the liquid gelatin stain is placed on a wet film on a warm slide of the organism under study. Observation is carried out on the warm stage after mixing and covering with a warm cover-glass. The bacterial cells appear pink against a blue background, the capsule remaining colourless. Thin films are easily prepared by this method. To assist differentiation and to prevent coalescence of capsules, the culture may previously be diluted with very dilute sodium hydroxide. This method does not involve drying or undue manipulation of the material and damage and distortion to the capsule are minimized. Observations of the capsules of both $A$. xylinum and $A$. oxydans by this method revealed a characteristically uniform appearance although slight differences in measurement, as compared with Indian Ink methods, were sometimes detected.

\section{RESULTS}

Cultures were obtained from apples and from juice. In the former case epidermal swabs were made and teased out and suspended in sterile water. After making suitable dilutions these were plated on suitable solid media. 
When examining juice for bacteria we found it convenient to centrifuge the samples and to wash the deposit with distilled water before making a film, as this avoided the juice charring or becoming a sticky mass.

The following morphological and cultural characters and biochemical reactions were found.

Solid media. On apple-juice agar and Blickfeldt's solution agar at $25^{\circ}$ the organism appeared barrel-shaped, with a tendency to be coccoid. After $24 \mathrm{hr}$. the colony appeared clear, colourless and circular with a mucoid tendency. After $48 \mathrm{hr}$. it appeared greyish and opaque and the mucoid tendency had increased. After $60 \mathrm{hr}$. it became grey-white, circular, refractile, entire edge, mucoid in texture, the centre uniform and slightly globose. After $\mathbf{7 0} \mathrm{hr}$. the colony was $2.5 \mathrm{~mm}$. in diameter, round, globose, grey-white in colour and opaque, thickly mucoid, entire edge, raised and less refractile than at $48 \mathrm{hr}$.

Slope cultures. At $24 \mathrm{hr}$. on apple-juice agar slopes, the colony was similar in appearance to that on agar plates. After $72 \mathrm{hr}$. the colony had begun to run along the surface towards the bottom of the slope. This was observed at $20^{\circ}$ and at $25^{\circ}$.

Apple-juice agar stab. Stab cultures at $25^{\circ}$ showed very slight growth along the line of inoculation for a distance of 5-6 mm. Good growth developed on the surface. After 3 weeks the growth was more luxuriant than that obtained by any other cultural method. After 6 weeks the surface had become stiff in texture. The colony was still viable up to 12 weeks at $20^{\circ}$ and $25^{\circ}$.

Gelatin media. No liquefaction in 3 weeks.

Liquid media. Under anaerobic conditions there was no growth in apple juice. Under aerobic conditions at $25^{\circ}$ the organism exhibited formation of diplococci with a tendency to short chain formation. After $48 \mathrm{hr}$. a slight surface scum appeared as a greyish white haze, which became uniform through the medium by $72 \mathrm{hr}$. and ultimately disappeared. After 7 days a thin greyish white film had spread over the entire surface, with a slight tendency to climb the walls of the glass. This film sank when disturbed.

Optimum temperature. The organism grew well at $20-25^{\circ}$, between $25^{\circ}$ and $30^{\circ}$ growth was less good, and above $30^{\circ}$ restriction became even more pronounced.

Motility. Neither cultures in sloppy gelatin nor liquid medium showed motile organisms.

Gas formation. Gas formation was not evident in aerobic culture in glucoseyeast water, ethanol-yeast water or acetic acid-yeast water at $25^{\circ}$.

Biochemical reactions. Acid was produced from glucose and sucrose accompanied by heavy growth, and from maltose, lactose, galactose, and dextrin with slight growth. There was very little growth and only a slight acid formation in the presence of raffinose. Acid was produced in the presence of $2 \%$ ethanol accompanied by fair growth.

Other characters. The organism was Gram-negative, catalase positive, nonspore forming, and gave a negative response to the Voges-Proskauer reaction. The presence of a capsule was demonstrated, by our own technique 
and by the methods of Gin and Baker. The following measurements were obtained:

Gin's method: $1.2 \times 1 \mu$. to $1.4 \times 1.2 \mu$.

Baker's method: $1.2 \times 1.2 \mu$. to $1.4 \times 1.5 \mu$.

Our method: $1.3 \times 1.3 \mu$. to $1.5 \times 1.5 \mu$.

\section{DISCUSSION}

Presence of a capsule, negative responses to Gram staining and the VogesProskauer reaction, absence of spore formation, production of catalase, together with ability to produce acetic acid from sugars and ethanol establish the organism as a species of Acetobacter. Non-oxidation of acetic acid, absence of pigment formation, and optimum growth at $20-25^{\circ}$ eliminates all the principal species in Bergey's Manual with the exception of $A$. oxydans. Bergey's Manual mentions, however, that motile forms of the latter organism occur and that the organism has been encountered in the form of rods, $0 \cdot 8-1.2 \times 2 \cdot 4-2 \cdot 7 \mu$., either singly or in chains. Another difference from our own organism is that according to Bergey's Manual, $A$. oxydans does not produce acid from lactose.

These differences may be reconciled by study of other publications. It is possible that our organism was cultivated at too high a temperature for motility to be observed, for Jorgensen (1939) remarked that Bact. oxydans [syn. $A$. oxydans (Henneberg) Bergey et al.] can be induced to produce motile cells by cultivation at $20^{\circ}$ on wort agar followed by transplantation into diluted beer. Shimwell (1948) confirmed that in many species of acetobacter motility sometimes occurs only at certain stages in the development of the culture. He also stated that although all members of the genus are rods, in some the cells are so short and so ellipsoidal and even coccoid in form that they are frequently mistaken for true cocci. Jorgensen also asserted that the cells of Bact. oxydans may appear in pairs or as fairly long chains.

The ability of our organism to produce acid from lactose and from other sugars is a characteristic shared by $A$. industrium (Henneberg), Bergey et al. Walker \& Tošić (1946b), however, claimed that $A$. oxydans can also produce acid from lactose, but Shimwell regarded $A$. oxydans and $A$. industrium as identical. Jorgensen makes a distinction between the two species for he remarked that although both organisms form a thin film on liquid media, that of $A$. oxydans tends to climb the glass (a characteristic exhibited by our organism), whereas that formed by $\boldsymbol{A}$. industrium falls to the bottom. On these grounds, therefore, we feel justified in identifying our organism as $A$. oxydans.

We wish to thank the Directors of Seager, Evans and Co., for permission to publish this paper.

\section{REFERENCES}

Bergey's Manual of Determinative Bacteriology (1948). 6th ed. edited by Breed, R. S., Murray, E. G. D. \& Hitchens, A. P., p. 179. London: Baillière, Tindall and Cox. Grove, O. (1915). The acetic bacteria of cider. Rep. agric. hort. Res. Sta. Bristol, p. 39. 
Jorgensen, A. (1939). Micro-organisms and Fermentation, 6th ed., p. 285. London: Charles Grifin and Co. Ltd.

Kulka, D. \& WAlker, T. K. (1946). Capsule formation by Acetobacter species. J. Inst. Brew. 52, 129.

Shimwell, J. L. (1948). Brewing bacteriology. IV. The acetic acid bacteria. Wallerstein Lab. Comm. 11, 27.

WALKER, T. K. \& Tošıć, J. (1943). The 'catalase test' with special reference to Acetobacter species. Biochem. J. 37, 10.

WaLker, T. K. \& Tošrć, J. $(\mathbf{1 9 4 6} a)$. A procedure for the characterization of the acetic acid bacteria. J. Soc. chem. Ind., Lond. 68, 104, 180.

WALKER, T. K. \& Tošıć, J. $(1946 b)$. The characterization and identification of acetic acid bacteria. J. Inst. Brew. 52, 238.

VANDECAVEYE, S. C. (1927). Studies of certain non-pellicle forming vinegar bacteria. J. Bact. 14, 1.

(Received 8 December 1951) 